\title{
NOTA SOBRE O SENTIMENTO DE EMBARAÇO EM ERVING GOFFMAN
}

\section{Carlos Benedito de Campos Martins}

Encounters are everywhere, but it is difficult to describe sociologically the stuff they are mad off. Erving Goffman

Goffman trouxe para o centro de sua sociologia a análise do problema da interação entre os atores sociais e estabeleceu uma relação entre ordem da interação e o sentimento de embaraço. A despeito das várias fases de sua obra - trabalhos pré-dramatúrgicos, investigações metafóricas, análise estratégica, teoria dos jogos, análise da linguagem, análise da estrutura das experiências individuais etc. - , o estudo da ordem da interação perpassou toda sua produção intelectual, estando presente desde sua tese de doutorado até o discurso presidencial na American Sociological Association, em 1982, que não chegou a ser lido por ele devido à sua morte prematura, ocorrida em no-

Artigo recebido em junbo/2008

Aprovado em julho/2008 vembro daquele ano. $\mathrm{O}$ problema do sentimento de embaraço recebeu um tratamento mais detalhado em seus trabalhos iniciais, porém essa temática foi retomada em publicações posteriores (Goffman, 1953, 1959, 1961a e b, 1967, 1971). O objetivo do presente trabalho é apresentar, de forma abreviada, a relação postulada por Goffman entre ordem da interação e sentimento de embaraço, procurando ressaltar que o percurso acadêmico do autor e as influências intelectuais que marcaram sua obra foram decisivos na análise dessa temática.

Não deixa de constituir um paradoxo que um dos pensadores mais influentes na sociologia norte-americana do século XX seja de origem canadense. Goffman nasceu em 1922, na pequena cidade de Manville, estado de Alberta, no interior de uma família de judeus imigrantes da Ucrânia. Paradoxalmente também sua formação acadêmica inicial não foi em sociologia, mas na área de química na Universidade de Manitoba, onde se graduou em 
1934. A sociologia foi introduzida naquela universidade somente no final dos anos de 1930. Durante o período entre 1943 e 1944, trabalhou no National Film Board of Canadá, em Ottawa, que produzia documentários. Certamente, essa experiência profissional teve um impacto posterior em seu refinado senso de observação dos comportamentos dos atores na vida social. Nesse período, travou amizade com o futuro sociólogo Denis Wrong, que o incentivou a se dedicar à sociologia (Fine et al., 2000, vol. 1, p. xi; Winkin, 1988, p. 21).

Em 1944, ingressou na Universidade de Toronto para iniciar seu treinamento em sociologia. Uma vez obtida a primeira etapa em sua formação nessa área, Goffman decidiu escolher uma universidade norte-americana para dar continuidade aos seus estudos, uma vez que os departamentos de sociologia canadenses ainda não estavam consolidados na oferta de pós-graduação. Sua opção recaiu sobre o Departamento de Sociologia da Universidade de Chicago, criado por Albion Small, em 1892, que, além de seu prestígio acadêmico, formou uma plêiade de professores que atuavam em diversos departamentos de sociologia então existentes no Canadá, especialmente na universidade de McGill, de Montreal. Deve-se acrescentar também que um encontro casual que Goffman manteve com Everett Hughes - canadense de origem e uma das figuras centrais do Departamento de Sociologia de Chicago - foi decisivo para reforçar sua escolha (Fine et al., 2000, vol. 1, p. xiii).

Sem dúvida, sua passagem pelo Departamento de Sociologia de Chicago marcou de forma indelével sua formação acadêmica. A defesa de sua dissertação de mestrado em 1949, denominada Some characteristic of responses do depicted experience, abordou a recepção de uma novela de rádio chamada Big Sister (Manning, 1992, p. 7; Winkin, 1988, p. 43). Após dezoito meses de coleta de informações numa comunidade situada numa das ilhas Shetland (Unst) na Escócia, defendeu sua tese de doutorado no final de 1953, intitulada Communication conduct in an Island community. Nas páginas iniciais desse trabalho, deixava claro que sua pesquisa não constituía um estudo de uma comunidade - temática cara a Warner, seu orientador -, mas focava sua atenção sobre o que ocorria durante as interações dos indivíduos no interior da comunidade (Goffman, 1953, p. 8).

Como foi salientado por Paul Colomy e David Brown, entre outros, havia uma inegável rela- ção entre o desenvolvimento do interacionismo simbólico e o Departamento de Sociologia de Chicago durante o período entre 1946 e 1952 (Colomy e Brown, 1984, p. 17; Fisher e Strauss, 1978, pp. 598-628). Certamente, diante da diversidade teórica e metodológica no interior do Departamento, alguns de membros manifestavam uma franca hostilidade a essa orientação teórica, além do que vários interacionistas não possuíam vinculação com a instituição. O empreendimento teórico de Blumer foi fundamental na constituição dessa vertente, cujo termo, interacionismo, foi cunhado por ele em 1937. Resgatando determinadas contribuições de G. H. Mead, Blumer insistiu sobre as dimensões interpretativa, contingente e transformadora da ação social. Investindo claramente contra a sociologia parsoniana, salientou que a ação social não constituía um produto de injunções de fatores externos, tais como normas, valores, sistema cultural etc., mas, ao contrário, ela era produzida nas interações que os atores estabelecem entre si (Blumer, 1986, p. 55). Por outro lado, Everett Hughes forneceu uma decisiva contribuição intelectual e pedagógica dentro do Departamento. Mais eclético metodologicamente do que Blumer, ao mesmo tempo em que usou uma variedade de dados em suas próprias pesquisas, insistia que os estudantes possuíssem uma formação em estatística. Hughes preferia a observação direta dos fenômenos sociais e, nesse sentido, teve um papel crucial na realização de estudos de campo por parte dos estudantes, o que constitui uma das marcas acadêmicas distintivas do Departamento de Sociologia de Chicago (Hughes, 1971; Fisher e Strauss, 1978, p. 599; Goffman, 1989, pp. 123-132).

Goffman era uma figura proeminente no interior de um grupo de jovens estudantes que foram treinados no ambiente intelectual de Chicago e que viria, posteriormente, ocupar uma posição de destaque no contexto da sociologia norte-americana, entre os quais se destacam Howard Becker, Ralph Turner, Joseph Gusfield, Helena Lopata, Kurt Lang, entre outros. De um modo geral, esses futuros pesquisadores adotaram uma postura cética com relação à dominação funcionalista e à sua ambição de desenvolver uma teoria geral sobre a sociedade, bem como procuraram distanciar-se da utilização de procedimentos quantitativos na realização de suas pesquisas. Forneceram, com seus trabalhos, uma contribuição para o florescimento de uma sociolo- 
gia interpretativa, levada adiante por investigações calcadas em minuciosas observações empíricas. Seus trabalhos tiveram um impacto posterior nas teorias do comportamento coletivo, da raça e da etnicidade, do trabalho e das ocupações, do desvio social etc. (Snow e Davis, 1995, pp. 188-220; Wacker, 1995, pp. 136-163; Galliher, 1995, pp. 164-187).

Ao longo de sua trajetória intelectual, Goffman transformou de forma criativa determinadasidéias de autores, entre os quais se destacam Durkheim, Radcliffe-Brown, Simmel, Charles Cooley, George Herbert Mead, Alfred Schutz, Kenneth Burke, Herbert Blumer e Everett Hughes, utilizando-os como referências tópicas para o desenvolvimento de seus próprios argumentos. Embora tenha sido associado à linhagem interacionista, na qual foi formado academicamente, não se enquadra facilmente em apenas uma tradição sociológica e jamais aceitou a filiação a essa abordagem. Numa das raras entrevistas que concedeu, marcou sua posição de distanciamento com relação ao interacionismo simbólico, à etnometodologia e ao construtivismo social (Verhoeven, 1993, pp. 324, 327, 334-335; Goffman, 1969, pp. 136-145). Explorando uma perspectiva analítica próxima de Kenneth Burke, incorporou também a contribuição de vários escritores, absorvendo de Marcel Proust sua aprimorada técnica de observação e descrição do comportamento humano. Em sua passagem por Paris, em 1951, tomou contato com a obra de Jean-Paul Sartre, no momento do apogeu do existencialismo, cuja reflexão sobre a dimensão da liberdade humana na vida social teve um impacto em sua obra. Diga-se de passagem, as citações de Sartre em seus trabalhos chegam a ser mais numerosas que as referências sociológicas tradicionais (Dean, 1983, pp. 1-32). Não apenas utilizou recorrentemente vários autores do campo literário como fonte de informação, mas incorporou também uma sensibilidade literária, o que o levou a desenvolver um estilo de escritura pouco convencional no interior da sociologia que contribuiu para que seus livros rompessem os limites da academia e fossem lidos por um amplo e diversificado público (Fine e Manning, 2003, p. 42; Collins, 1994, pp. 218-219; Burke, 1969).

Tal como Parsons, Goffman estava preocupado em analisar uma questão clássica nas ciências sociais, qual seja, o problema hobbesiano da ordem social (Parsons, 1968, pp. 89-113, 346-389; Wrong, 1994, pp. 158-171). Ao contrário de Parsons, que procurou fornecer uma explicação a partir de uma visão macro sobre as bases institucionais que possibilitam a ordem social, Goffman estava interessado fundamentalmente em compreender os mecanismos que sustentam os processos da interação entre os indivíduos, o que ocorre em microssituações sociais concretas. Nesse sentido, ressaltou que a vida social se desenvolve no seu cotidiano a partir de relações face a face que estão submetidas a determinadas regulações, tais como: um conjunto de prévias experiências culturais vivenciadas pelos indivíduos que as utilizam em seus encontros; um estoque de impressões que voluntária ou involuntariamente transmitem sobre si mesmos; um conjunto de informações e/ou inferências que possuem a respeito dos demais integrantes de um processo interacional; a existência de expectativas que os atores nutrem de serem tratados em função do valor social que reivindicam para si mesmos (Sheff, 2006, p. 42). Ao mesmo tempo em que enfatizou o caráter ordenado e recorrente das interações, sua análise evidenciou a fragilidade, a precariedade e a instabilidade existentes nessas interações e o enorme potencial de ruptura que circunda e ameaça constantemente as relações interacionais (Kim, 2003, pp. 55-65; Colomy e Brown, 1984, p. 36).

Ao longo de sua carreira, Goffman partiu do pressuposto de que a organização social e a estrutura social constituíam a essência da sociologia, chegando a afirmar que considerava a sociedade em primeiro lugar e o indivíduo logo em seguida (Goffman, 1974 , p. 13; Treviño, 2003, pp. 12-13). No entanto, foi justamente sobre o processo de envolvimento dos indivíduos uns com os outros que Goffman concentrou uma parte significativa de seu esforço intelectual. Nas sociedades modernas, em seu entendimento, existia uma crescente desconexão entre a organização social no nível macro e a micro-ordem interacional, situação essa que ele denominava loose coupling (Goffman, 1983, p. 11). Sua obra, de certa forma, inverteu o prisma do paradigma parsoniano a respeito da relação entre estrutura social e ator ao acentuar o impacto da ordem interacional na dinâmica das estruturas sociais mais amplas. Para ele, os diferentes tipos de organizações sociais dependem do conjunto de pessoas que nelas trabalham e que em situações concretas executam suas tarefas. Em sua visão, a dinâmica interna das organizações sociais, tais como transmissão de informações, coordenação de tarefas e tomadas de 
decisões, são vulneráveis ao funcionamento das relações face a face.

Tais relações que os indivíduos travam entre si em situações sociais concretas constituem um domínio de investigação analiticamente distinguível - a ordem de interação -, que possui estruturas, processos e regularidades específicas, não podendo ser reduzida a situações macrossociais e cujo método adequado de investigação repousa na microanálise. Tal como Blumer, Goffman assinalou a centralidade do processo interpretativo e do caráter contingente da ação social. No entanto, ao recuperar a contribuição de Willian Thomas sobre o impacto que $a$ definição da situação possui sobre o comportamento que os indivíduos desenvolvem entre si, Goffman enfatizou que as condições situacionais e institucionais afetam, informam e circunscrevem as ações sociais no tempo e no espaço (Thomas, 1966, pp. 154-167; Colomy e Brown, 1984). Nesse sentido, insistiu que a compreensão da trama interacional deve levar em consideração a existência de situações sociais específicas, nas quais os indivíduos se encontram fisicamente presentes, desenvolvem seus comportamentos, interpretam e respondem às ações dos demais participantes envolvidos nesse processo, ou seja, a ordem interacional não constitui uma produção meramente local. Para ele, as situações sociais específicas expressam uma realidade sui generis, constituindo, portanto, a unidade básica da ordem da interação e o terreno social onde ela efetivamente ocorre (Goffman, 1964, pp. 134; 1983, p. 2). Seria oportuno assinalar que Goffman utilizou em seus trabalhos diferentes termos intercambiáveis para referir-se ao indivíduo, tais como self, role, person, identity, sendo que às vezes todos esses termos aparecem num mesmo livro, dando margens para ambigüidades conceituais. No entanto, a respeito dessa questão, o conceito fundamental em Goffman é o de self, que longe de constituir uma dimensão psicológica localizada e fixada no interior do indivíduo, é o resultado de um processo social. Dessa forma, o self não constituiu uma propriedade da pessoa, mas reside no padrão de controle social que é exercido pela pessoa e por aqueles que a cercam. Sua análise trouxe, com isso, o self para o centro da ordem interacional. Nas situações de encontros sociais, o que está em jogo não é a totalidade da pessoa humana, mas uma de suas dimensões, tal como o status social que é exercido naquele momento, enfim, um self específico (Goffman, 1956b: 58; 1961a: 142).
Em seu discurso de posse na American Sociological Association, salientou que o fato de os indivíduos participarem no processo interacional in sito, com seus próprios corpos, torna-os fisicamente vulneráveis, uma vez que podem se expor a possíveis atos de seqüestro, roubo, molestações sexuais e, eventualmente, ter seus movimentos físicos obstruídos. A sociologia de Goffman procurou acentuar a existência de uma significativa carga emocional que perpassa o processo interacional, na medida em que no seu desenrolar pode surgir, de forma acidental, determinadas situações que criam sentimentos de desconforto, ansiedade, medo, vergonha e humilhação para os atores envolvidos nesse processo. Entre esses sentimentos que podem emergir durante o desenrolar da trama interacional, Goffman privilegiou o de embaraço, que expressa uma sensação de desconforto experimentado eventualmente nas relações interacionais. Em sua análise, o sentimento de embaraço possui relevância social, pois liga os nervos da organização social à conduta do dia-a-dia. A possibilidade latente de sua ocorrência suscita uma atitude de coação nos indivíduos em seus encontros sociais de modo a evitar possíveis ações que possam ser consideradas problemáticas e contribuir para desacreditá-los socialmente. O sentimento de embaraço desempenha, portanto, um papel importante no envolvimento dos atores com valores e convenções existentes na organização social. Em sua visão, ele permite a recorrência da vida cotidiana e o estabelecimento de nossas transações com os seus participantes (Sheff, 2006, pp. 15-18; Heath, 1988, p. 137; Schudson, 1984).

Tal sentimento deriva de um descompasso entre a projeção social realizada por um indivíduo e eventuais acontecimentos que podem emergir durante o desenrolar de uma interação que a contradiz. Quando alguém informa o que ele é socialmente, de certa forma exerce uma exigência moral sobre os participantes da interação, uma vez que espera que seja tratado de acordo com a categoria social à qual julga pertencer. Para Goffman, ao mesmo tempo, os demais participantes estão constantemente interpretando a conduta do ator que realiza uma determinada performance social, mesmo que não tenham inteira consciência desse expediente. Simultaneamente, o indivíduo que está projetando um selfprocura aceitar a definição e a representação dos selfs projetados pelos outros. A questão crucial no surgimento do sentimento de embaraço 
encontra-se relacionada com a real ou imaginada presença dos outros e o decorrente desafio apresentado aos atores em manter um razoável controle da situação na qual se encontram envolvidos (Goffman, 1956a, pp. 264-265).

O processo interacional repousa num trabalho de produção de um consenso operacional construído conjuntamente pelos participantes nele envolvidos - por meio de sensibilidade diplomática, tato humano e savoir-faire -, no qual tendem a apoiar valores aos quais todos os presentes prestam falsa homenagem e evitar determinados assuntos que poderiam comprometer o modus vivendi que está sendo construído. Na medida em que a sustentação da definição da situação deriva de um empreendimento coletivo, a unidade apropriada de análise não repousa no indivíduo isolado e seu aparato psicológico, mas nas relações construídas entre as diferentes pessoas que se encontram presentes. Nessa perspectiva, Goffman reivindica uma sociologia das ocasiões, capaz de analisar o empreendimento interacional, uma vez que seu trabalho busca analisar não o homem em seus momentos, mas os momentos e seus homens (Goffman, 1967, pp. 2-3).

O momento de crise na ordem da interação que abre espaço para a emergência do sentimento de embaraço - surge quando um determinado evento contribui para colocar em dúvida a reivindicação que o indivíduo elaborou sobre uma dimensão do seu self, minando os pressupostos que sustentavam uma determinada situação e abrindo caminho para um possível sentimento de descrédito social. Mesmo em interações que se desenrolam de forma razoavelmente equilibrada e pacífica podem ocorrer pequenos eventos involuntários, como um fauxpas, uma gaffe, que podem solapar a impressão que alguém procurava transmitir. Em nenhum momento o ator possui completo domínio do fluxo de acontecimentos que podem ocorrer durante uma situação específica, bem como não detém controle absoluto sobre as possíveis informações que os demais participantes eventualmente armazenaram sobre sua pessoa e que porventura podem utilizar numa circunstância específica. Durante o processo interacional, o indivíduo, ao perder momentaneamente seu controle muscular, pode gaguejar, arrotar, ter uma flatulência, bocejar, escorregar, tropeçar etc. Ao apresentar dificuldades em manejar seu comportamento emocional, pode expressar preocupação excessiva ou demonstrar pouco interesse na representação do outro, apresentar ainda um comportamento de grande ansiedade, ter um uma explosão de riso ou de raiva, incapacitando-o momentaneamente de dirigir de forma adequada sua ação etc.

$\mathrm{Na}$ medida em que determinados fatos perturbadores ocorrem no transcorrer de um processo interacional, interrompendo seu desenrolar, cria-se um sentimento de embaraço entre seus participantes. Para Goffman, um indivíduo reconhece tal sentimento nos outros e em si mesmo quando surgem sinais objetivos de distúrbios corporais e emocionais, como a presença de sinais avermelhados no rosto, transpiração em excesso, perda do domínio da comunicação verbal, evidente tremor nas mãos, dificuldade no manejo do olhar, exibição de um sorriso fixo, articulação incoerente das idéias etc. Nessa circunstância, seus participantes descobrem que o acordo tácito, celebrado explícita ou implicitamente que vinha sustentando e orientando suas condutas no interior de uma definição da situação estava equivocado. Nesse momento, o minúsculo sistema da interação entra em colapso, gerando uma situação de anomia e um sentimento de constrangimento para o indivíduo cuja representação foi desacreditada. Ao mesmo tempo, a ruptura interacional possibilita também o surgimento de sentimentos como desnorteamento, hostilidade e vergonha, e uma sensação de confusão entre os demais participantes. Goffman ressalta, ainda, que nesse processo de desmoronamento do little social system o sentimento de embaraço contamina, contagia e infringe um sofrimento social a todos os participantes, sendo que o indivíduo que eventualmente contribuiu para desacreditar um outro se sente também envergonhado e culpado, pois, ao destruir a imagem do outro, ele destrói sua própria imagem como ator capaz de se comportar de forma hábil e diplomática em situações interacionais delicadas.

A possibilidade da ocorrência do sentimento de embaraço alimenta um dos dramas centrais da vida social, uma vez que engendra nos atores a necessidade de desenvolver um contínuo comportamento de performance ao longo de suas vidas. Mais do que uma metáfora para explicar a vida social, a dramaturgia associada ao desempenho de papéis in sito constitui um elemento central da atividade humana, moldando a vida cotidiana dos atores. Como argutamente observou Michael Schudson, a sociologia de Goffman, ao assumir o pressuposto 
de que o sentimento de embaraço possui uma profunda significância moral, descreveu o ator social mais voltado em evitar e minimizar possíveis riscos durante o processo interacional - desenvolvendo estratégias de autopromoção e autodefesa - do que em maximizar ganhos sociais. Na medida em que uma simples nota fora de compasso pode comprometer uma performance social em sua totalidade, homens e mulheres, de forma consciente e/ou inconsciente, conduzem suas vidas procurando a todo custo evitar situações de embaraço que podem corroer as imagens projetadas de si mesmos e, eventualmente, conduzi-los à ruína e ao descrédito social (Shudson, 1984, p. 634; Treviño, 2003, p. 14).

Ao proclamar que o homem na qualidade de objeto sagrado pode ser exposto a situações de profanação, Goffman tornou-se um etnógrafo do self e erigiu como uma das marcas distintivas de sua sociologia uma apaixonada defesa contra as forças sociais ou as circunstâncias que contribuem para desacreditar ou oprimir alguém, sejam provenientes de homens comuns ou de representantes oficiais de instituições (Goffman, 1967, p. 31). Em The presentation of self in everyday life, o autor enfoca o problema da sustentação do self em instituições profissionais, domésticas, comerciais, industriais, ou seja, em estabelecimentos típicos da vida cotidiana. Embora sempre exista o risco potencial da quebra da definição da situação que pode conduzir ao descrédito social, nessas instituições os atores estão razoavelmente equipados socialmente para preservar o self projetado e inclinados a desenvolver um trabalho de cooperação no sentido de protegê-los. Nessas circunstâncias, a possibilidade de uma ruína pessoal é mais literal do que real, e o preço a ser pago é o sentimento de embaraço, que pode ser eventualmente contornado por um conjunto de maneiras sociais desenvolvidas por atores que buscam preservar a definição da situação.

No entanto, existem outras condições sociais nas quais o self pode ser profundamente desafiado, atacado e desacreditado. Diante dessas situações, a obra de Goffman - sem utilizar juízos de valor assume implicitamente uma eloqüente e apaixonada defesa da dignidade do self e põe em relevo as diversas estratégias que visam à sua preservação. Em Asylum, escrito numa linguagem fria, porém contundente, há uma descrição detalhada de como as instituições totais - caracterizadas por ele como "estufas para mudar pessoas, um experimento natural sobre o que se pode fazer ao eu" -, ao exercerem controle estrito sobre o self, o expõem a seguidos atos de humilhações e mortificações, ameaçando a perda da identidade do indivíduo e conduzindo-o a uma desfiguração social (Goffman, 1961a, pp. 29-36; Becker, 2007, pp. 223-237). Em Stigma, o universo de análise afasta-se da descrição do interior das instituições totais e retorna seu foco para a vida cotidiana, salientando como o self pode ser completamente desacreditado e ameaçado de ser destruído. Sua análise incide sobre a enorme tensão existente entre os indivíduos estigmatizados física e/ou socialmente, ou seja, que possuem atributos socialmente depreciativos, e os outros que não possuem essas características. O livro inicia com uma passagem do romance de Natanael West, Miss Lonelyhearts, na qual uma jovem de 16 anos narra seu infortúnio de não possuir um nariz, o que assusta as pessoas, afasta-a dos garotos e faz sua mãe chorar intensamente quando olha para ela. A escolha desse romance, escrito em 1933, não poderia ser mais apropriada ao tema tratado por Goffman, uma vez que West retrata um mundo urbano corroído pela depressão de 1930, povoado por pessoas defeituosas fisicamente, por indivíduos traídos sentimentalmente, impotentes sexualmente e derrotados socialmente, que escrevem cartas narrando seus infortúnios e profunda dor a um jornalista responsável pela sessão de auto-ajuda de um jornal nova-iorquino, solicitando conselhos para reparar a deterioração de suas identidades e atenuar seus sofrimentos.

Em sua perspectiva, as relações face a face não deveriam ser vistas apenas em termos de constrangimento, riscos e ameaças, uma vez que existe nas sociedades uma dualidade fundamental de comportamentos com relação aos atores, abrangendo situações em que tanto podem ser tratados de forma ofensiva como ser objetos de cortesia e respeito. Numa perspectiva próxima de Durkheim, Goffman assinalou que a ordem social se baseia em obrigações morais, em rituais de respeito e deferência com relação ao caráter sagrado do self. Nessa direção, o autor confere um papel central nos gestos amistosos e nas pequenas bondades cotidianas que os atores desenvolvem entre si como mecanismos de preservação da ordem interacional. A violação do território do self significa o solapamento de possíveis laços de generosidade que os atores podem desenvolver entre si (Goffman, 1963, p. 8; 1956b, pp. 485-487; 1971, pp. x-xi; Gouldner, 1970, 
pp. 379-381; Rawls, 1987, p. 144). De maneira perspicaz, seus trabalhos, direta ou indiretamente, estavam atentos ao que posteriormente no debate sociológico passou a ser referido como as mediações entre estrutura e ator. Ao mesmo tempo, é possível identificar em suas análises que os indivíduos, em larga medida, são controlados, determinados por forças sociais, tais como instituições, papéis sociais, contextos situacionais etc. Por outro lado, Goffman evidencia como os indivíduos procuram afirmar e preservar sua autonomia e dignidade pessoal diante do poder de forças estruturais mediante uma variedade de pequenas estratégias de resistência, como as de secundary adjustment, role distance, managing spoiled adjustments etc., mesmo que não consigam obter um autodomínio absoluto de seus atos. Dessa forma, a presença das circunstâncias institucionais e estruturais no desenvolvimento da ação social não elimina o papel ativo que os indivíduos exercem no interior da vida social (Goffman, 1961a, pp. 54-63; 1961b, pp. 105-115; Freidson, 1983, pp. 359-361; Treviño, 2003, pp. 203-214).

As obras de Erving Goffman e de seus colegas de geração que passaram pelo Departamento de Sociologia da Universidade de Chicago tiveram um forte impacto nas ciências sociais contemporâneas, introduzindo no seu interior novos temas de investigação e uma particular sensibilidade analítica em seu tratamento, o que contribuiu decisivamente para a renovação da agenda de pesquisa. Goffman integrou forma criativa as contribuições da sociologia, da antropologia, da sociolingüística, da etologia etc., o que lhe permitiu edificar uma obra que ultrapassou, de forma deliberada, os limites convencionais que demarcavam os territórios das disciplinas acadêmicas. Diversos autores contemporâneos que ocupam uma posição destacada nesse campo disciplinar, como Bourdieu, Giddens, Habermas, Randall Collins, Jeffrey Alexander, mantêm-se muito interessados nos escritos de Goffman, procurando direta ou indiretamente estabelecer um diálogo constante com as perspectivas inovadoras a respeito das microinterações, no sentido de obter uma compreensão mais clara das complexas relações existentes entre as estruturas institucionais e a dimensão da agência dos atores sociais. Passados 25 anos de sua morte, os trabalhos de Goffman continuam sendo lidos e possui uma presença destacada no interior das ciências sociais. Certamente, o estímulo intelectual que sua obra é capaz de des- pertar e o prazer da leitura de seus escritos, elaborados numa linguagem satírica, sarcástica, humorada, desconcertante, continuarão fertilizando a pesquisa das novas gerações de cientistas sociais.

\section{BIBLIOGRAFIA}

BECKER, Howard. (2007), Telling about society. Chicago, The University of Chicago Press.

BLUMER, Herbert. (1986), Symbolic interacionism: perspective and method. Los Angeles, University of California Press.

BURKE, Kenneth. (1969), A grammar of motives. Los Angeles, University of California Press.

CALHOUM, Craig \& VAN ANTWERPEN, Jonathan (2007), "Ortodoxy, heterodoxy and hierarchy: 'mainstream' sociology and its challengers", in Craig Calhoum (org.), Sociology in American: a history, Chicago, The University of Chicago Press.

CAMIC, Charles. (1996), "Three departments in search of a discipline: localism and interdisciplinary interaction in American Sociology, 1890-1940". Social Research, 62 (4).

COLLINS, Randall. (1994), Four sociological traditions. Nova York, Oxford University Press.

COLLOMY, Paul \& BROWN, David. (1984), "Elaboration, revision, polemic and progress in the Second Chicago School", in Gary Fine (org.), A Second Chicago School? The development of a postwar American sociology, Chicago, The University of Chicago Press.

DEAN, MacCannell. (1983), "Erving Goffman (1922-1982)". Semiotica, 45 (1/2).

FINE, Gary \& MANNING, Philip. (2003), "Erving Goffman", in George Ritzer (org.), The Blackwell Companion to major comtemporary social theorists, Oxford, Blackwell Publishing.

FINE, Gary Alan; MANNING, Philip \& SMITH, Gregory. (2000), Erving Goffman. Londres, Sage, 4 vols.

FISHER, Berenice \& STRAUSS, Anselm. (1978), "Interactionism", in Tom Bottomore e Robert Nisbet (orgs.), A history of sociological analysis, Nova York, Basic Books.

FREIDSON, Eliot. (1983), "Celebrating Goffman". Contemporary Sociology, 12 (4).

GALLIHER, John. (1995), "Chicago two worlds of deviance research: who's side are they on?”, 
in Gary Fine (org.), A Second Chicago School? The development of a postwar American sociology, Chicago, The University of Chicago Press.

GOFFMAN, Erving. (1953), Communication in an Island community. PhD. Dissertation, Department of Sociology, University of Chicago. . (1956a), "Embarrassement and social organization”. American Journal of Sociology, 62 (3). . (1956b), "The nature of deference and demeanor". American Anthropologist, 58 (3). . (1959), The presentation of self in everyday life. Nova York, Anchor Books.

. (1961a), Asylums: essays on the social situation of mental patients and other inmates. Nova York, Doubleday Anchor.

(1961b), Encounters: two studies in the sociology of interaction. Indiannapolis, The BobbsMerril Company.

- (1963), Behavior in public places: notes on the social organization of gatherings. Nova York, Free Press.

. (1964), "The neglect situation". American Anthropologist. 66 (6).

- (1967), Interaction ritual: essays on face to face behavior. Nova York, Pantheon Books.

. (1969), Strategic interaction. Philadelphia, University of Pennsylvania Press.

. (1971), Relations in public: microstudies of the public order. Nova York, Basic Books.

. (1974), The frame analysis. Nova York, Harper.

. (1983), "The interaction order". American Journal of Sociology, 48 (1). . (1989), "On fieldwork". Journal of Contemporary Ethnography, 18 (2).

GOULDNER, Alvin. (1970), The coming crisis of Western sociology. Nova York, Basic Books.

GUSFIELD, Joseph. (1995), "The Second Chicago School", in Gary Fine (org.), A Second Chicago School? The development of a postwar American sociology, Chicago, The University of Chicago Press.

HEATH, Christian. (1988), "Embarrassement and interational organization", in Paul Drew (org.), Erving Goffman: exploring the interaction order. Cambridge, Poliy.

HUGHES, Everet. (1971), The sociological eye: select papers. Nova York, Aldin-Atherton.

KALBERG, Stephen. (2007), "A cross-national consensus on a unified sociological theory?
Some inter-cultural obstacles". European Journal of Social Theory, 10 (2).

KIM, Kwang-Ki. (2003), Order and agency in modernity: Talcott Parsons, Erving Goffman and Harold Garfinkel. Albany, State University of New York Press.

KURTZ, Lester. (1984), Evaluating Chicago sociology. Chicago, The University of Chicago Press.

MANNING, Philip. (1992), Erving Goffman and the modern sociology. Stanford, Stanford University Press.

PARSONS, Talcott. (1968), The structure of social action. Nova York, The Free Press.

RAWLS, Anne. (1987), “The interaction order sui generis: Goffman's contribution to social theory". Sociological Theory, 5 (20).

SCHUDSON, Michael. (1984), "Embarrassement and Erving Goffman's idea of human nature". Theory and Society, 13 (5).

SHEFF, Thomas. (2006), Goffman unbound: a new paradigm for social science. Londres, Paradigm Publishers.

SNOWN, David \& DAVIS, Phillip. (1995), "The Chicago approach to collective behavior", in Gary Fine (org.), A Second Chicago School? The development of a postwar American sociology, Chicago, The University of Chicago Press.

THOMAZ, William. (1966), On social organization and social personality. Chicago, The University of Chicago Press.

TREVIÑO, Javier. (2003), Goffman's legacy. Nova York, Rowman \& Littlefield Publishers.

VERHOEVEN, Jef. (1993), "An interview with Erving Goffman". Research on Language and Social Interaction, 26 (3).

WACKER, Fred. (1995), “The sociology of race and ethnicity in the Second Chicago School", in Gary Fine (org.), A Second Chicago School? The development of a postwar American sociology, Chicago, The University of Chicago Press.

WINKIN, Yves. (1988), "Les moments et leurs homes". Paris, Seuil/Minuit.

WRONG, Dennis. (1994), The problem of order: what unites and divides society. Nova York, The Free Press. 


\section{NOTAS SOBRE O SENTIMENTO DE EMBARAÇO EM ERVING GOFFMAN}

\section{Carlos Benedito Martins}

Palavras-chave: Ordem social; Ordem interacional; Projeção social do self; Sentimento de embaraço.

O objetivo do presente texto é apresentar de forma abreviada a relação postulada por Goffman entre a ordem de interação e o sentimento de embaraço. Procuramos também, de maneira esquemática, salientar determinadas influências intelectuais que marcaram a elaboração de sua obra. Nesse sentido, destacamos sua passagem pelo Departamento de Sociologia de Chicago e sua complexa relação com a postura analítica interacionista.

\section{NOTES ON THE FEELING OF EMBARRASSMENT IN ERVING GOFFMAN}

\section{Carlos Benedito Martins}

Keywords: Social order; International order; Social projection of the self; Feeling of embarrassment.

The objective of this paper is to briefly present the relation postulated by Goffman between the order of interaction and the feeling of embarrassment. We have also schematically sought to emphasize certain intellectual influences that have marked the making of his work. That way, we highlight his passing through the Sociology Department of Chicago and his complex relation with the interactionist analytical posture.

\section{NOTES À PROPOS DU SENTIMENT D'EMBARRAS DANS ERVING GOFFMAN}

Mots-clés: Ordre social; Ordre international; Projection sociale du self; Sentiment d'embarras.

L'objectif de ce texte est de présenter, de façon résumée, la relation postulée par Goffman entre l'ordre de l'interaction et le sentiment d'embarras. Nous avons également cherché, de façon schématique, de souligner certaines influences intellectuelles qui ont marqué l'élaboration de son œuvre. Ainsi, nous rappelons son passage par le Département de Sociologie de Chicago et son rapport complexe avec la posture analytique interactive. 